\title{
Correction to: European Society for Paediatric Oncology (SIOPE) MRI guidelines for imaging patients with central nervous system tumours
}

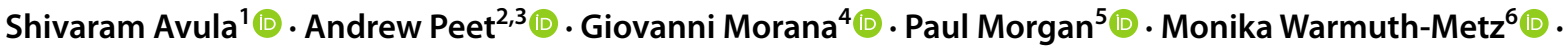 \\ Tim Jaspan ${ }^{7}$ (1) - European Society for Paediatric Oncology (SIOPE)-Brain Tumour Imaging Group
}

Published online: 19 July 2021

๑) Springer-Verlag GmbH Germany, part of Springer Nature 2021

\section{Correction to: Child's Nervous System \\ https://doi.org/10.1007/s00381-021-05199-4}

The original version of this article unfortunately contained an error. Table 2 went missing in the published version; hence, given here is the missing table.

The original article has been corrected.

The original article can be found online at https://doi.org/10.1007/ s00381-021-05199-4.

Shivaram Avula

shivaram.avula@alderhey.nhs.uk

1 Department of Radiology, Alder Hey Children's NHS

Foundation Trust, East Prescot Road, Liverpool L14 5AB,

UK

2 Institute of Cancer and Genomic Sciences, University of Birmingham, Birmingham, UK

3 Birmingham Women's and Children's Hospital NHS Foundation Trust, Birmingham, UK

4 Department of Neurosciences, University of Turin, Turin, Italy

5 Department of Medical Physics, Nottingham University Hospitals, Nottingham, UK

6 Institute of Diagnostic and Interventional Neuroradiology, University of Würzburg, Würzburg, Germany

7 Department of Radiology, Nottingham University Hospitals, Nottingham, UK 
Table 2 Spine imaging

\begin{tabular}{|c|c|c|c|}
\hline \multicolumn{4}{|l|}{ Essential Sequences* } \\
\hline Sequence & Technique & Parameter & Plane \\
\hline \multirow[t]{2}{*}{$\mathrm{T}_{1} \mathrm{~W}+$ Contrast } & \multirow[t]{2}{*}{ 2D SE/TSE } & Slice thickness $\leq 3 \mathrm{~mm}$ & \multirow[t]{2}{*}{$\begin{array}{l}\text { Sagittal whole spine } \\
\text { (entire dural sac) }\end{array}$} \\
\hline & & Slice gap $<0.5 \mathrm{~mm}$ & \\
\hline $\mathrm{T}_{1} \mathrm{~W}+$ Contrast & $\begin{array}{l}\text { 2D SE/TSE or } \\
\text { 3D gradient }\end{array}$ & $\begin{array}{l}\text { Slice thickness } 4-5 \mathrm{~mm} \\
\text { No slice gap }\end{array}$ & Axial-suspicious areas* \\
\hline Sequence & & Technique & Plane \\
\hline \multicolumn{4}{|c|}{ Matrix size-Minimum 256 (512 is desirable for better resolution) } \\
\hline \multicolumn{4}{|l|}{ Optional Sequences } \\
\hline $\mathrm{T}_{2} \mathrm{~W}$ & & 2D SE/TSE & Sagittal whole spine \\
\hline $\mathrm{T}_{2} \mathrm{~W}$ & & 2D SE/TSE & Axial-suspicious areas \\
\hline Heavily weighted $\mathrm{T}_{2} \mathrm{~W}$ & & 2D or 3D CISS/B FFE/FIESTA** & Sagittal \pm axial \\
\hline
\end{tabular}

*In primary tumours of the spinal cord, $\mathrm{T}_{2} \mathrm{~W}$ andpre contrast $\mathrm{T}_{1} \mathrm{~W}$ sequences are essential ** The heavily weighted $\mathrm{T} 2 \mathrm{~W}$ sequence localised to a region of interest is useful in assessment of drop metastasis

Publisher's Note Springer Nature remains neutral with regard to jurisdictional claims in published maps and institutional affiliations. 